\title{
To imitate or differentiate: Cross-level identity work in an innovation network
}

\begin{abstract}
Survival in global high-tech industries requires many organizations to participate in specialized innovation networks. However, sustained participation in these networks often proves more challenging than expected for organizations and their representatives, due to complex crosslevel identity tensions that are indiscernible when only one level of analysis is considered. The purpose of this study is to analyze cross-level identity tensions at the interface of personal and organizational identities in an innovation network. We identify three key cross-level identity tensions related to intellectual property, communication and market definition, which together contribute to an overall organizational-personal identity tension opposing differentiation and imitation. These tensions are indicative of a complex process of "partial isomorphism" in identity work, which can facilitate collaboration while simultaneously fostering innovation among personal and organizational network members.
\end{abstract}

\section{Introduction}

Organizations operating in highly competitive industries frequently invest time and money in innovation networks in order to stay abreast of new developments, build connections, and at times, embark on new collaborative ventures. But meeting network requirements and remaining attractive to potential partners can pose significant challenges to these organizations and their employees. Participants in such collaborations can fall victim to free riding, opportunism, escalating commitment, redundant information (Oliver, 2004), resource misappropriation, project stagnation, cynicism, over-collaboration and even excessive innovation surpassing individual and organizational absorptive capacities (Katila, Rosenberger \& Eisenhardt, 2008). Furthermore, while research networks can indeed generate innovations, they sometimes also result in attitude similarity, imitation, and varying levels of performance, leading to calls for additional study of dynamic tradeoffs occurring at multiple levels (Brass, Galaskiewicz, Greve \& Tsai, 2004). 
The high-tech aerospace industry is characterized by rapid change and intense, globalized competition, requiring continuous research and development (R\&D) investments. Complex products (e.g., planes, drones, helicopters and satellites) have given rise to complicated supply chains and shared R\&D through innovation networks, as organizations attempt to increase market share. Such innovation networks not only promote resource concentration, risk distribution and intellectual property sharing among industrial, academic and governmental organizations, but also increase the occurrence and intensity of interaction among representatives, which can reverberate all the way up to interorganizational relations (Chreim, Williams \& Hinings, 2007; Marchington \& Vincent, 2004).

Interorganizational research networks also present cross-level identity challenges (Huemer, Becerra \& Lunnan, 2004). Originating as an individual-level construct in the field of psychology, the notion of identity has been extended to the collective and organizational levels, where it continues to offer a personal frame of reference that legitimizes decision-making and enables the formation of stable relationships with others (Oliver, 2015). Identity has been connected to many organizational phenomena, including the formulation of strategy, the enactment of leadership, intergroup conflict, employee pride (Ashforth, Rogers \& Corley, 2011), and organizational development (Jacobs, Oliver \& Heracleous, 2013). Far from being a static attribute, identity is constantly interpreted, reflected upon, and gradually formed within social interactions (Alvesson \& Willmott, 2002).

Identity work refers to processes engaged in by individuals related to "forming, repairing, maintaining, strengthening or revising the constructions that are productive of a sense of coherence and distinctiveness” (Sveningsson \& Alvesson, 2003: 1165). Studies of identity work have tended to focus on active processes of identity construction, including ways in which people make connections "outwards" to social others as well as "inwards" to the self (Watson, 2008: 140). However, processes of identity work also are characterized by tensions between individual notions of who and what one is (self-identity), and cultural, discursive or institutional notions of who or what any individual might be (social-identity) (Watson, 2008). Tracy and Tretheney (2005) urged scholars to “explore the shifting, fluid, and potentially liberatory identity tensions in a world in which people are accustomed to striving for a stable self” (2005: 185). 
Although individuals may be attempting to construct a coherent sense of self, they can also be "read" in terms of more than one social identity (Watson, 2008). This tension between the inside and the outside occurs at each level of interaction (e.g., intrapersonal vs. interpersonal, intraorganizational vs. interorganizational). Similarly, identity tensions may occur between levels of interaction, such as between the interpersonal level and the interorganizational level. Such cross-level tensions are particularly prevalent in the context of multi-organizational research networks or consortia where the intellectual property is owned by the organizations. However, cross-level research on identity and identity work has generated more theoretical than empirical interest in the literature to date, despite the broader potential to help bridge levels of analysis in organization studies research (Kreiner, Hollensbe \& Sheep, 2006).

The goal of this study is to analyze the cross-level tensions that influence identity work in the interface between interpersonal and interorganizational relationships in a research consortium. The Canadian aerospace industry is home to the world's third largest aerospace cluster in Montreal (Emerson, 2012), which includes a number of organized innovation networks involved in interorganizational $\mathrm{R} \& \mathrm{D}$ projects. We explain and further conceptualize the everyday interactions among individuals representing different organizational members of a Montreal-based aerospace research consortium. In particular, we focus on the cross-level tensions impacting identity work occurring at the personal and organizational levels among consortium participants. Our analysis reveals three tensions related to intellectual property (protecting vs. concealing), communication (translating vs. decoding), and market definition (competing vs. collaborating). These tensions give rise to an overall tension between differentiation and imitation at the personal and organizational levels.

We begin this article by briefly situating our argument in the literatures on identity work and cross-level tensions, before integrating notions of identity in networks. We subsequently describe our methodology and our case study. Our findings section presents the grounded analysis leading to our four specific cross-level tensions. Finally, we discuss our results in the context of the literature on cross-level identity work, and present some conclusions and directions for future research.

\section{Identity work and cross-level tensions}


Identity work potentially encompasses a vast array of activities; Brown (2015) enumerated an impressive number of descriptive verbs used in the literature, including claim, accept, comply, resist, and define. ${ }^{1}$ Generally speaking, identity work relates to how individuals locate themselves as social and organizational beings, and endeavor to construct a coherent sense of self (Alvesson, Ashcraft \& Thomas, 2008). It includes internal reactions to suggested external identities, such as ways in which individuals align their personal identities with collective identities in organizations (Ashforth, Harrison \& Corley, 2008; Alvesson et al., 2008; Alvesson \& Willmott, 2002). This ongoing and largely internal struggle may not be openly expressed, as individuals "perceive themselves to be under varying degrees of obligation to speak from a particular identity position by the social obligations implicit to the prevailing interactional context” (Brown, 2015: 29). Identity work may become especially salient and intense in episodes characterized by crises, tensions or constraints (Brown, 2015; Breit, 2014), or when triggered by some clash or discrepancy between identity and disconfirmation (Alvesson \& Robertson, 2015). In their study of an opera company, Beech, Gilmore, Cochrane and Greig (2012) identified key identity tensions associated with enacting an aspirational identity, distancing from parts of self from which one wishes to dis-identify, and managing the contradictions inherent in hybrid identities. Cross-level tensions are also evident during "remedial organizational identity work" (Breit, 2014) whereby organizational members attempt to remedy, threaten or damage organizational identities.

Individuals work on identities for themselves, others and on behalf of collectives, alone or in aggregate. Thus, identity work involves linking everyday micropractices (communications, emails, conversations, informal routines, etc.) with macroprocesses (formal discourses, materiality, hierarchies, and contracts), whereby multiple levels of interaction affect the organic, complex process of identity construction. In their article about internal (intra-identity) and external (extra-identity) interfaces between personal and organizational identities, Kreiner et al. (2006) described internal boundaries between identity dimensions at each identity level as “permeable” or “impermeable.” Personal and organizational identities may thus be conceived as

\footnotetext{
${ }^{1}$ Other verbs used in the identity work literature include: separate, join, limit, bound, stabilize, reconcile, (re)structure, differentiate, manufacture, regulate, distance, contest, improvise, craft, deny, (re)act, (re)shape, (re)think, acquiesce, rebel, conform, enact, construct, acquire, lose, switch, modify, adjust, evolve, (re)negotiate, flex, adapt, enable, facilitate, direct, usurp, control, impede, hinder, establish, discard, (re)formulate, and (re)narrate (Brown, 2015).
} 
permeable or impermeable to one another, potentially leading to a negotiation of shared or independent identity dimensions at each level. Identity work thus also relates to the negotiation of identities between levels of interaction, since suggested external "superordinate identities" impose constraints on suggested external "nested identities" (Kane, 2010), while facilitating knowledge transfer (Argote \& Kane, 2009). Identities at each level of analysis can thus simultaneously enable and constrain identities at other levels, maintaining a degree of cross-level isomorphism (Ashforth et al., 2011).

Identity permeability/impermeability is also observable in the language used by organizational members. Drawing on work by Kreiner et al. (2006) and Ellis and Ybema (2010), Ashforth et al. (2011) described three mutually-influencing processes in the cross-level coconstruction of identity: intrasubjective (“I think”), intersubjective ("we think”) and subjective generic ("it is"). Identity work occurs within the structural arrangements of organizations and the multiplicity of discourses that affect interactions and alter the relationships between individuals (McInnes \& Corlett, 2012). Whether internalized or not, discourses are external resources that enable individuals to establish themselves as distinctive and valued, while delimiting what can be said and done in ongoing conversations. Identity work can thus "be experienced as tensions between different social duties and rights associated with being a particular-type-of-individual” (McInnes \& Cortlett, 2012: 29). Actors can choose ways to combine or hold competing discourses in tension as part of their continued growth of a "crystallized self" (Tracy \& Trethewey, 2005: 188). The metaphor of identity as a seemingly stable crystal suggests that there are always new "facets" of one's identity that are relevant to a context and ready to be polished, cleaved, or transformed. "By conceiving of identities as ongoing, emergent, and not entirely predictable crystals, people are forced to acknowledge a range of possible selves embodied in a range of contexts” (Tracy \& Trethewey, 2005: 189).

\section{Identity work in a network context}

Most studies on identity work to date have focused on a single level of analysis (Ashforth et al., 2011), such as personal (Clarke, Brown \& Hailey, 2009; Watson, 2008) or organizational (Clegg, Rhodes \& Kornberger, 2007). The complex process by which different identities mold and are molded—especially possible interactions between different identity levels (Ashforth et 
al., 2011; Kreiner et al., 2006) as well as the dynamic interaction between personal and organizational identities (Kreiner et al., 2006)—remains little understood in a network context (Ibarra, Kilduff \& Tsai, 2005). Indeed, processes of reciprocal causation and coevolution concerning individuals and the networks in which they are embedded have generally been neglected by social science scholars (Ibarra et al., 2005). Researchers who investigate interorganizational relationships typically study dyads at the organizational level (Ashforth et al., 2011; Hitt, Beamish, Jackson \& Mathieu, 2007; Brass et al., 2004), whereas individuals in real networks interact on behalf of organizations in multiple, complex relationships. Those who take a network perspective focus on relationships as facilitators and/or inhibitors of actors' actions (Johansson \& Elg, 2002) and identities:

Each company in a network has a unique position in relation to the other actors, but the position of a company is perceived differently by the various actors in the network...The position of an actor is also shaped by its business partners to some extent. Their actions and reactions demonstrate their perceptions of the company's position and further reinforce it. (Gadde, Huemer \& Håkansson, 2003: 362)

Nevertheless, an emerging stream of studies about identities in networks indicates that internal identities can be influenced by focal personal or collective actors, while external identity can be influenced by other actors in the network (Huemer, Håkansson \& Prenkert, 2009). An actor can appear trapped between ambitions to control personal development and the influence of all related network actors who are trying to use him or her in their own development (Huemer et al., 2009: 54). The success of an actor in a network depends on his or her ability to deal with these tensions rather than avoid them:

[Identities in networks] emerge and are constructed through an interplay between internal features and successful control, and the internal features of others and their successful influence; and new demands created either by new positions in old networks or entering into entirely "new” networks. (Huemer et al., 2009: 70)

Similarly, findings in the network literature predict that interactions in many contexts tend to result in increasing social homogeneity, similarity of choices, and structural equivalence or “isomorphism” (Borgatti \& Halgin, 2011; Borgatti \& Foster, 2003), while managers must consciously strike a balance between internal non-negotiables and external influences (Huemer, 2013). Isomorphism in networks can occur through "convergence” from evolving in similar environments while social homogeneity occurs through “contagion” that occurs through interaction (Borgatti \& Foster, 2003) or four “diffusion processes” of apprenticeship, mimetism, 
coercion, and osmosis (Borgatti \& Halgin, 2011). In this study, we define isomorphism as the social homogenization of the actors in a network through contagion, convergence, apprenticeship, mimetism, coercion, and/or osmosis.

Tensions in cross-level identity work can occur between pressures toward isomorphism reflecting a need for coherence within the network, and opposing pressures for increased differentiation (Ashforth et al., 2011). While collaboration and knowledge transfer in networks have been found to be facilitated by the establishment of a "moral community" (Browning et al., 1995), establishing such a community can require managers to draw on mutually-antagonistic discursive resources (Clarke et al., 2009), and engage in effective discursive “positioning” (Ellis \& Ybema, 2010). It is this use of language that we explore in this study.

\section{Method}

We performed a single case study of multiple embedded levels (Yin, 2003: 40) of an organization to investigate the interpersonal and interorganizational relationships at the Consortium of Research and Innovation in Aerospace in Quebec (CRIAQ). In doing so, we sought to address the question: How do cross-level identity tensions play out in an innovation network? In addition to enabling and constraining organizational and personal identities, these cross-level tensions might be expected to influence the evolution of the network overall. CRIAQ is a revealing example of an innovation network within which individual members act on behalf of both themselves and their respective organizations, which means that one of the units of analysis (interpersonal relationships) is embedded in the other (interorganizational relationships). Although some representatives’ activities have more impact on organizational actions and decisions, the extent to which an organization "acts” is seen as a reflection of its numerous representatives’ activities.

We adopted a purposeful and stratified sampling strategy (Patton, 2002: 244) to ensure that we interviewed representatives with different individual characteristics who also represented different types of organizations: small and medium enterprises (SMEs), original equipment manufacturers (OEMs) and academic organizations (AOs). Some of the initial interviews revealed that in addition to being unique individuals who fulfilled different roles for their respective organizations and possessed specific expertise and pursued distinct goals, 
representatives were classified and evaluated by other representatives according to the organizations (typically the types of organizations) they belonged to, leading us to introduce the term type of individual. Thus, this single case includes six distinctive types of interpersonal relationships that may be conveniently compared, almost as if there were six unique cases: (a) relationships between academic and SME representatives; (b) relationships between academic and OEM representatives; (c) relationships between OEM and SME representatives; (d) relationships between academic representatives; (e) relationships between OEM representatives; and (f) relationships between SME representatives. These six interpersonal relationships were replicated at the organizational level.

Each of the relationships was described by many actors involved in one or many of them, but also by third parties who witnessed them, greatly contributing to literal replication (Yin, 2003: 48). Cross-case comparisons of distinct relationships at both levels made differences more salient by theoretical replication (Yin, 2003: 48). Our relational approach thus enabled us to avoid some of the pitfalls of classical approaches to comparing organizational subgroups such as project teams, units or departments, and was well-suited to the specific features of an R\&D consortium.

A small number of SME representatives per organization fulfilled many roles in the consortium, whereas dozens of OEM and university representatives fulfilled specialized roles in the consortium or on their respective projects. Therefore, one interview with the most knowledgeable informant from each organization was deemed to be sufficient. For OEMs and universities, the most knowledgeable informant often was a specific person in charge of project coordination and/or definition for all organizational projects.

As stated in the consortium documents, each research project had to include at least two company organizations and two academic organizations. One company leader and one academic leader were then identified. Typically, the academic leader was in charge of applying for government funding aimed at promoting industry-university collaborations, and for assembling an academic team comprised of university students (from undergraduates to postdoctoral students) to conduct the research as part of an internship, master or doctoral thesis work, or with the goal of producing a scientific publication. Once government funding was secured, company partners and the consortium each matched a quarter of the amount (which doubled the total 
funding) and all partners signed an intellectual property agreement. Twelve research themes were clearly identified within the consortium. Actors with expertise in the same research theme were therefore far more predisposed to interact with each other on a regular basis. Moreover, because the innovation network was not limited to the consortium in practice, informants at times extended their responses to refer to collaborations outside the consortium that involved the “same types of partners and the same dynamics” (OEM representative). As a result, the study of this consortium holds broader implications for the entire aerospace cluster in Montreal.

\section{Data collection and analysis}

We collected data over a 2-year period from three main sources: internal and external documents, interviews, and observations (see Table 1 for a description of our data). We iteratively triangulated these data by engaging in multiple in-depth rounds of analysis and making several presentations of preliminary results to consortium organizers and academic colleagues during different stages of the analysis.

\section{Table 1: Data sources}

\begin{tabular}{|c|c|c|}
\hline Source & Type & Number \\
\hline \multirow[t]{6}{*}{ Observations } & Conferences & 25 \\
\hline & Research committee meetings & 7 \\
\hline & Project management workshops & 6 \\
\hline & Information sessions & 2 \\
\hline & Intellectual property formation & 1 \\
\hline & Administration committee meeting & 1 \\
\hline \multirow[t]{2}{*}{ Documents } & Internal documents (reports) & 40 \\
\hline & $\begin{array}{l}\text { Online documents (websites, reports, scientific articles, } \\
\text { patents, theses, etc.) }\end{array}$ & $100+$ \\
\hline \multirow{4}{*}{$\begin{array}{l}\text { Semi-structured interviews } \\
\text { (38 informants representing } 40 \\
\text { organizations) }\end{array}$} & OEMs & 6 \\
\hline & SMEs & 15 \\
\hline & Universities and research centers & 17 \\
\hline & Consortium & 2 \\
\hline
\end{tabular}

The data analysis strategy is derived from grounded theory (Corbin \& Strauss, 2008). Our grounded analysis led us to develop categories by extracting patterns (codes, categories, relations, processes) from the raw data, and coding them using NVivo software. We proceeded iteratively, going back and forth between early emerging categories, literature and new data in order to develop a theoretical model explicitly supported by data. Early descriptions and constant 
comparisons of codes resulted in the merging or splitting of many categories. The number of codes from different sources indicated the importance of a concept, but an overly large number of references to a single code relative to other codes led us to segment it into smaller units in order to balance the relative importance of final codes. Similarly, an overly small number of references to a single code meant the concept needed to be merged into a bigger category or abandoned as a relevant dimension of analysis.

We followed a series of four steps to analyze the data. First, we initially considered representatives (SME representatives, OEM representatives and academic representatives) in isolation and then compared them with individuals from the same and different types of organizations (Corbin \& Strauss, 2008) in order to identify differences and similarities in broad characteristics such as personal motivations, interests, activities, and resources. We determined the organization type (SME, OEM or AO) based on the verbal accounts of consortium representatives (interviews and observations) and information in shared documents. Second, we considered personal relationships between representatives in isolation and then compared them with others to identify differences and similarities in general areas such as personal goals motivating the formation of the relationship, personal roles fulfilled by each party, the nature of exchanges, and power relationships. Third, we considered organizations in isolation and compared them with organizations of the same and different types in order to identify differences and similarities related to organizational motivations, interests, activities and resources. Fourth, we considered organizational relationships between OEMs, SMEs and AOs in isolation and compared them with one another in order to identify differences and similarities reflecting the organizational goals motivating the formation of the relationship, the organizational roles fulfilled by each party, the nature of exchanges, and power relationships. Finally, we identified ideas (whole sentences) that had been coded in more than one category (including different levels of analysis) and examined them more closely.

\section{Within-level and cross-level tensions}

The coding process allowed for the identification of four cross-level tensions - three constituent and one overall (see Table 2 for descriptions of our categories). While we considered an extensive number of personal and organizational codes, we focused most intently on codes related to cross-level interactions. The tensions we identified existed at the interpersonal or 
interorganizational levels (within-level tensions), or between the levels of analysis (cross-level tensions). Consistent with Järventie-Thesleff and Tienari’s (2015) conception of roles as mediators in identity work, linked codes gradually appeared as an emerging characteristic, as collaborating partners often discussed their relationships by referring to interorganizational and interpersonal roles on projects, dichotomous dimensions justifying the collaboration, or a delicate balance between two processes. Cross-level tensions gradually appeared as delicate equilibria between two processes defined by these linked codes within levels of interaction.

Representative quotes leading to the identification of the cross-level tensions are provided in the text, in each case building on an analysis of tensions at the personal and organizational levels.

\section{Table 2: Four key identity tensions}

\begin{tabular}{|c|c|c|c|c|}
\hline \multicolumn{2}{|r|}{ Tension } & Personal level & Organizational level & \multirow{3}{*}{\begin{tabular}{l}
\multicolumn{1}{c}{ Cross-level } \\
Personal publications could \\
potentially violate nondisclosure \\
agreements and inhibit organizational \\
patents. Unprotected innovations \\
should remain confidential.
\end{tabular}} \\
\hline \multirow{2}{*}{ 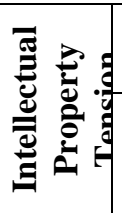 } & IP Protecting & $\begin{array}{l}\text { Personal } \\
\text { publications }\end{array}$ & Organizational patents & \\
\hline & IP Concealing & $\begin{array}{l}\text { Personal access, } \\
\text { formation, and } \\
\text { security }\end{array}$ & Nondisclosure agreements & \\
\hline \multirow{2}{*}{ 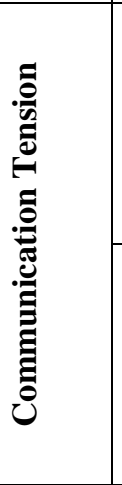 } & $\begin{array}{l}\text { Partially } \\
\text { Translating }\end{array}$ & $\begin{array}{l}\text { An individual } \\
\text { partially translates } \\
\text { oneself, or another } \\
\text { (type of) individual } \\
\text { or organizational } \\
\text { actor. }\end{array}$ & $\begin{array}{l}\text { An organization, through } \\
\text { its representatives, } \\
\text { partially translates (a type } \\
\text { of) individual or } \\
\text { organizational actor. }\end{array}$ & \multirow[t]{2}{*}{$\begin{array}{l}\text { Partially translating hinders the } \\
\text { decoding of actors within and across } \\
\text { levels. Partially decoding only allows } \\
\text { an actor to partially translate another } \\
\text { actor within and across levels. }\end{array}$} \\
\hline & $\begin{array}{l}\text { Partially } \\
\text { Decoding }\end{array}$ & $\begin{array}{l}\text { An individual } \\
\text { partially decodes } \\
\text { another (type of) } \\
\text { individual or } \\
\text { organizational } \\
\text { actor. }\end{array}$ & $\begin{array}{l}\text { An organization, through } \\
\text { its representatives, } \\
\text { partially decodes one } \\
\text { (type of) individual or } \\
\text { organizational actor. }\end{array}$ & \\
\hline \multirow{2}{*}{ 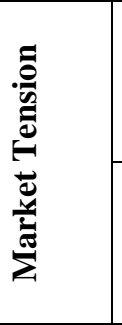 } & Competing & $\begin{array}{l}\text { An individual } \\
\text { competes with } \\
\text { another (type of) } \\
\text { individual. }\end{array}$ & $\begin{array}{l}\text { An organization, through } \\
\text { its representatives, } \\
\text { competes with another } \\
\text { (type of) organization. }\end{array}$ & \multirow{2}{*}{$\begin{array}{l}\text { Competition at both levels hinders } \\
\text { collaboration. Collaboration at both } \\
\text { levels is possible if actors are distinct } \\
\text { enough at least at one level. } \\
\text { Competition at one level hinders } \\
\text { collaboration at the other level if } \\
\text { actors are too similar at least at one } \\
\text { level. }\end{array}$} \\
\hline & Collaborating & $\begin{array}{l}\text { An individual } \\
\text { collaborates with } \\
\text { another (type of) } \\
\text { individual. }\end{array}$ & $\begin{array}{l}\text { An organization, through } \\
\text { its representatives, } \\
\text { collaborates with another } \\
\text { (type of) organization. }\end{array}$ & \\
\hline \multirow{2}{*}{ 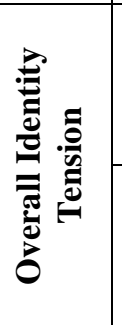 } & Imitating & $\begin{array}{l}\text { An individual } \\
\text { imitates another } \\
\text { (type of) } \\
\text { individual. }\end{array}$ & $\begin{array}{l}\text { An organization, through } \\
\text { its representatives, } \\
\text { imitates another (type of) } \\
\text { organization. }\end{array}$ & \multirow{2}{*}{$\begin{array}{l}\text { Imitating another actor decreases the } \\
\text { differences between them and } \\
\text { increases competition within and } \\
\text { across levels. Overly-high } \\
\text { differentiation hinders collaboration } \\
\text { within and across levels. }\end{array}$} \\
\hline & Differentiating & $\begin{array}{l}\text { An individual } \\
\text { differentiates away } \\
\text { from another (type } \\
\text { of) individual or }\end{array}$ & $\begin{array}{l}\text { An organization, through } \\
\text { its representatives, } \\
\text { differentiates away from } \\
\text { another (type of) }\end{array}$ & \\
\hline
\end{tabular}




\begin{tabular}{|l|l|l|l|}
\hline & $\begin{array}{l}\text { organizational } \\
\text { actor. }\end{array}$ & $\begin{array}{l}\text { individual or } \\
\text { organizational actor. }\end{array}$ & \\
\hline
\end{tabular}

The cross-level dimensions represent subtle tensions and ongoing difficult choices to be made contextually in everyday practice by organizations and their representatives, with important implications for identity (co)reproduction and (co)construction. We build on each cross-level tension by first describing the personal- and organizational-level tensions. Personallevel tensions exist between individuals, whereas organizational-level tensions exist between representatives of different organizations. Quotes illustrating within-level and cross-level tensions were at times difficult to classify as such, especially when one of the two dimensions delimiting a tension at times appeared only implicitly. In such cases, we considered longer quotes to include more contextual information. Some quotes were also difficult to analyze due to the unintentional or unconscious usage of unclear pronouns and reference groups. In this sense, our levels of analysis were not always empirical realities in the minds of actors. Finally, organizations do not talk or act per se. Rather, individuals talk and act on behalf of organizations, regardless of their legitimate right to do so or their real impact on the perceptions of an organization.

When invited to describe how they and their organizations were distinct from other actors in the context of the consortium, informants tended to refer to organizational intellectual property, personal and organizational expertise, collaborators and competitors, and specific abilities that were useful and valued in the context of the consortium such as interpersonal communication, networking, public relations or interpretation abilities. Many informants also referred to information sought by the consortium, learning targets such as best management practices, emergent high-value expertise in the industry, newly available resources to acquire, desirable contacts to establish (individuals or organizations), and other valuable strategic information to be gathered. Most of these identity-relevant dimensions were subjective and needed to be negotiated between the different (types of) actors; that is, they were worked on externally as well as internally. Even the question of who was a competitor to whom could not be assumed to be perceived in the same way by different parties, as more powerful actors tended to pay less attention to less powerful players. These personal and/or organizational identity dimensions intersect in four processes of identity work described in our findings. 


\section{Findings}

We present our findings in two sections. First, we describe the three constituent identity tensions related to intellectual property, communication, and views on markets that emerged from the data analysis, followed by the overall identity work tension evident at both levels and across levels of analysis, namely the need to both differentiate and imitate. In all cases, we draw on quotes from network informants to describe our findings. Figure 2 presents these identity tensions, from the more focused constituent tensions between personal and organizational IP, communication and market definition, to the higher-level overall tension between differentiation and imitation of personal and organizational identities.

Figure 1: Cross-level identity work tensions in an innovation network

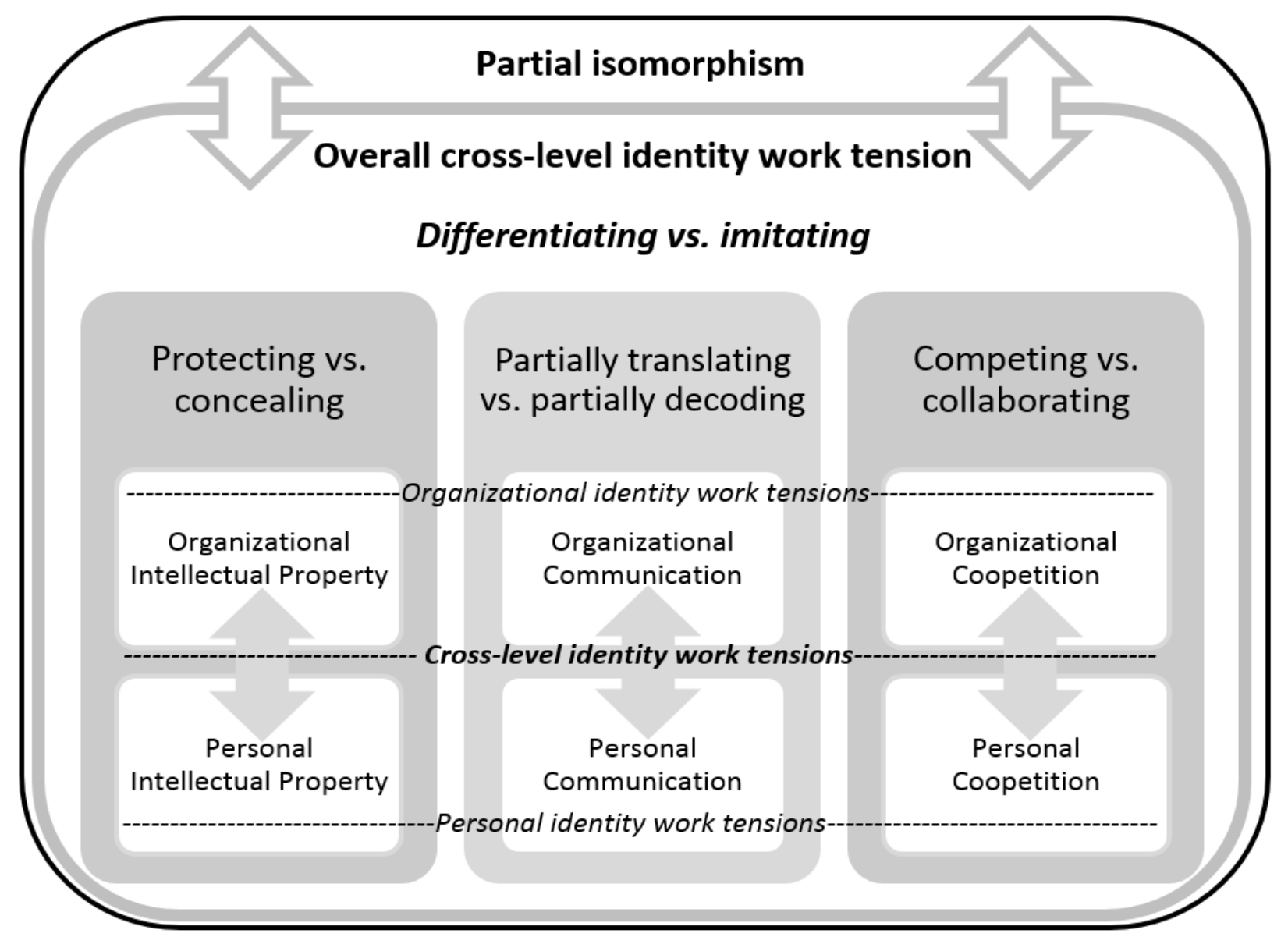




\section{Identity tension 1: Protecting vs. concealing intellectual property}

This cross-level tension relates to the necessity to maintain confidentiality (or “conceal”) intellectual property (IP) not yet protected by formal mechanisms such as publications or patents. Once IP is protected by such mechanisms, it becomes more easily accessible and no longer concealed. Intellectual property remained a constant source of conflict between personal and organizational interests while contributing to identity construction by creating a source of personal and organizational differentiation. Individual confidentiality was enforced by organizations with non-disclosure agreements specifying both the new IP that was anticipated to be generated by the project, as well as any prior organizational IP that needed to be shared within the project. Although innovations were considered organizational property in the formal consortium agreement, threats of confidential information leaks (intended or not) came from individuals.

At the personal level, publications were highly valued by academics and justified their initial involvement in projects. Although obvious for academics, the need to publish results often came as a surprise for consortium participants from the business world, complicating certain collaborative activities.

If the professor mentions, "I'm not sure the project is interesting for us because I don't see what we can publish,” right from the start I refuse [the collaboration] because I know his life ideal is to publish. I know it's required but you can’t build a team around this. (OEM2, Product Architect)

Publications contributed to academics’ identity distinctiveness; however, they also potentially threatened organizational IP and the exclusivity of personal expertise. Tensions emerged when individuals, such as government-funded interns, sought access to unprotected IP in order to conduct research and be trained in specific technologies. Interns were perceived as more legitimate and less of a threat to companies’ IP than publications by partners — indeed, many were eventually hired by host organizations. "You give students opportunities to understand what it means to work on industrial specifications, and afterwards [they] better integrate on a team in a firm” (SME2, R\&D Coordinator). However, confidential information leaks could come either from one individual or through an accumulation of comments from many individuals, thus 
involving organizations in the tension. Even when information disclosure could be clearly identified, it often remained difficult to connect leaks to specific individuals. In terms of identity work, some individuals sought to present themselves as trustworthy, sometimes stating that they trusted each other not to use or reveal unprotected IP in order to support innovation. In other instances, academics suddenly became more focused on confidentiality, refusing to share publishable results — even among organizational colleagues - to the detriment of companies involved in the project: "How can you know the [organizational] IP the student created for the project in the project is available for all the [organizational] partners? You can't know it for sure in these cases!” (OEM2, Product Architect).

At the organizational level, patents were critical for organizations and constituted a primary motivation for investing in these projects. An organization's patent portfolio often impacted the organization's value and identity, particularly IP that was considered "core." Organizational IP protection appeared to be a greater issue when an organization possessed a limited portfolio of patents coupled with limited resources in case of infringement-the situation for most SMEs. In the aerospace industry, organizations at lower levels of the supply chain had to reveal more information related to their services and products to organizations at higher levels for security and traceability reasons. On the other hand, organizations at higher levels often owned the IP rights for parts ordered from suppliers: "The ultimate goal is to produce parts for the client who's gonna own the intellectual property anyway” (SME1, R\&D Executive). Although individual patents were possible, the consortium IP agreement stated that the IP specifically developed within collaborative projects belonged equally to all organizations involved in the project, regardless of their respective contributions. This agreement often created suspicion among the partners: "We're under the impression some [organizational] partners only put a little cash into the pool to access the intellectual property. They do nothing on the project but give the minimum cash” (OEM2, Product Architect). Usually, at least one organization had "core” IP involved in the project, but leaks could come from any partner. As a result, a strong sense of organizational identification sometimes led representatives to conceal organizational IP in the absence of formal protection mechanisms. In the case of academic representatives, personal identity work related to publication possibilities similarly increased IP concealing behaviors, especially for unanticipated results of the project not included in the initial agreement. 
Across levels, personal publications potentially violated nondisclosure agreements and inhibited organizational patents. Individuals signed non-disclosure agreements with their organizations, project partners, and the consortium. Since publications were valued principally by academics, and patents were valued mostly by companies (through their representatives), considerable tension stemmed from the fact that one protection mechanism could block the other: "We need to lose a little [organizational] intellectual property to allow professors to publish” (OEM1, R\&D Coordinator). Even though the stakes were difficult to evaluate, constant suspicion appeared to be the norm on most projects. "If there's too much pressure on one side, we'll only give them what they need to know and keep the goodies for ourselves” (AO1, R\&D Coordinator). Organizational IP protection sometimes proved to be in conflict with several personal goals, such as publications, training and security. Partners signed the IP agreement based on the predicted outcomes of the collaborative R\&D project, but unanticipated results of the project remained outside of the agreement. These agreements lasted for several years, during which time the content of the innovation had to remain confidential. The fact that the consortium also engaged in high-security defense sector research also influenced cross-level identity tensions related to partner selection at times: "We have many projects on which our professors, our students, cannot work because of their citizenship” (AO2, Faculty Dean).

Overall, the IP identity tension created implications for the personal identity work of academics who defined themselves (and their counterparts) based on the number of publications they had and their relative prestige. At the organizational level, the number of patents held by an organization was linked to its expertise, competitiveness and value, its power over others, and the future of research in a particular area. Therefore, determining which outputs of a project could be published—and who had access to IP in the meantime- led to ongoing struggles between personal and organizational actors: "We maintain good [personal] relationships but in reality we are [organizational] competitors, so information sharing and innovation between [individual] partners will be more difficult considering we don't necessarily want to share what we will develop with them” (SME3, R\&D Project Manager). IP confidentiality also played an important role in the communication tension we describe next.

\section{Identity tension 2: Partially translating vs. decoding communications}


During interviews, informants frequently alluded to the ability to explain someone's reality to another and the corollary capacity to decode a partner's messages. Translating refers to the act of converting one vocabulary into another across various boundaries (Carlile, 2004). Effective translating provides an audience with better resources with which to comprehend an actor's identity, thus it can be considered as a form of identity work. In the context of this research network, translation often involved converting one discipline's jargon into another (e.g., electrical into mechanical engineering), one community of practice's vocabulary into another (e.g., academic into business), various occupational terms (e.g., related to strategy, project management and marketing) and literal translation from one language into another (in this case, French and English). Individuals translated their academic or corporate needs, large players translated their requirements to smaller players (and vice versa), and representatives regularly spoke on behalf of several academics or business partners as they participated in various consortium activities. While translation processes sometimes led to unintentional confusion, translators at times filtered their messages in strategic ways.

Parallel to translating, decoding involves transforming sensory input into significant interpretation(s) through listening, reading and perceiving nonverbal signs, and requires an ability to recognize possible unintended confusion in the translation (Henderson, 2004). Effective decoding requires an in-depth knowledge of underlying industry dynamics and acute political skills, including the ability to identify elements that have been strategically concealed by partners. In the process, interpretations are made by the decoder who uses his or her identity as an information filter that makes communications appear more or less threatening, suspicious or encouraging. Actors thus decode messages in order to confirm their interpretations of other identities, as well as their own.

The capabilities of translating and decoding information constitute inter-linked skills representing two sides of the same coin. A translation is inherently "partial” to the extent that tacit knowledge is difficult to completely translate into explicit knowledge (Carlile, 2004); yet translation choices can also be "strategic" due to voluntary selection of information. Thus, a decoder may find it difficult to determine whether a translation was unintentionally partial, or a kind of strategic choice involving the withholding of information. Although all partners had some competence in translating and decoding as they engaged in both processes, the nature of 
partial translation could impact another's ability to decode, and representatives themselves varied greatly in their decoding abilities. Some skilled decoders appeared to be aware that strategic considerations were impacting translation:

Sometimes, my technical staff doesn't even understand because the doctoral student gets into a bunch of calculations. In these cases it becomes useless, but the professor lets it go on because they're professors having fun this way. (OEM1, R\&D Coordinator)

At the personal level, individuals (representatives) decoded other individuals, types of individuals, organizations or types of organizations. In parallel, individuals partially translated themselves, as well as other individuals, types of individuals, organizations or types of organizations, in a form of identity work. Individuals who were able to successfully translate and decode were highly valued by consortium members: "He’s technically and academically very good but he’s also able to speak to us. There are a few” (OEM1, R\&D Coordinator). Partially translated individual intentions and goals had to be decoded, and did not always match the organizational objectives of the translator. Regardless of whether information was voluntarily omitted or concealed by individuals or organizations, experience enabled decoders to more effectively challenge popular assumptions: “Some people are proficient in theory, meaning they have a never-ending CV but are perfectly incapable of organizing anything” (SME2, R\&D Coordinator). The effectiveness of the translating and decoding processes varied greatly from one representative to another, and often led to conflicts. Frequent interaction and familiarity with many individuals from a single organization at times supported the process of decoding individuals, as well as organizations and types of organizations.

At the organizational level, organizations (through their representatives) decoded or partially translated individuals, types of individuals, organizations or types of organizations. A representative who engaged in partial translation selected information that aligned with the formal discourse and organizational identity promoted by the organization. The partial translations of several individuals attached to the same organization made it possible for one observer to connect messages into a more or less coherent organizational message: "These are firms' strategies to plug their products and access big players. For many, it's only about product placement” (OEM2, Product Architect). So the decoding also occurred as individuals crosschecked and aggregated different messages, and evaluated differences in the messages 
communicated by different representatives of the same organization. Representatives who engaged in partial translation also selected their information carefully, and their messages were decoded in different ways by others:

The SME was editing the data they were presenting to us, not necessarily lying, but presenting it in a way to show their product was better than what's available today. No lies, only a different way to organize the message. (OEM1, R\&D Coordinator)

In this situation, an OEM representative decoded "the SME" (including its representatives) as manipulative, and excluded the organization from any future projects with the OEM. The identity work here involved labeling the other organization (the SME) as untrustworthy, which implied the opposite characteristic for the focal organization (the OEM).

Across levels, individual actors at times partially translated information from their organizations, while partially decoding information received from other actors. On occasion, actors first decoded and then translated in order to speak on behalf of a group of organizations of a specific type (e.g., OEMs) to an individual belonging to another type of organization (e.g., an $\mathrm{AO})$ :

The ideal [personal] company leader is someone able to gather [company representatives] together and speak with one voice as companies, saying: "Here are the needs of the industry.” Yes we might have specific [organizational] needs. It's all right. But we must lead the industry to speak with one voice. This way, the [personal] academic leader only has one message. (OEM1, R\&D Coordinator)

In this case, identity work occurs on superordinate identities - " "the industry,” and implicitly, academia — and involves a context-sensitive reflexive account of the differences between these locally relevant groups from the perspective of a company representative directed toward an academic representative. This quote highlights the possibility that several potentially conflicting messages (translations) delivered by different company representatives to one academic representative might be misinterpreted when decoded into a coherent industrial message. This possibility created the need for company representatives to personally translate different organizational needs into a clear industrial message to be communicated to the academic representative in order to decrease the amount of decoding effort required. Translation 
inconsistencies were frequently evident among representatives, even those from the same enterprise:

Enterprises see their interest in both [consortia], forgetting the necessity, if not of a [industrial] convergence, of at least a coherent [organizational] message conveyed by each enterprise [representative] in each [consortium]. (AO2, Faculty Dean)

This informant referred to variations in the translations of the same organizational message delivered by two different representatives from the same organization in different consortia leading to a lack of a "coherent" organizational message, as well as two different translations of the same industrial message by two representatives of different organizations in the same consortia leading to a lack of industrial “convergence.” In terms of identity work, even though some organizations openly admitted that they would not share information in any context and thus presented themselves as extraordinarily protective, others strategically attempted to claim transparency — claims that were nonetheless highly controversial among other consortium members and decoded as questionable at best. The general difficulty encountered in translating and decoding other actors' messages made it even more difficult to determine if an identity was authentic, unintentionally confusing or strategically ambiguous.

What made this identity work tension so significant was the strategic aspect of the translation and decoding processes at both the personal and organizational levels. The identities actors were attempting to construct influenced their translation processes as well as the decoding interpretations made by others. One might argue that the defense industry, which operates in a highly confidential manner, sets the tone for the entire aerospace industry; however, the high risk investments and global competition that characterize the aerospace industry equally contribute to this tendency towards secrecy, as shown by the first identity tension and this second identity tension, which builds on it. In the next section, we describe another central dimension that directly affected the extent to which members engaged in strategic partial translation or decoding: the tension between competition and collaboration.

\section{Identity tension 3: Competing vs collaborating in markets}


When asked what made themselves and their organizations distinctive from other actors in the consortium, individuals often referred to those with whom they either collaborated or competed. Interestingly enough, these perceptions were not always reciprocal among their counterparts, and these varying interpretations thus constituted an important contextual aspect of identity work. For example, categorizing other actors as competitors could be interpreted as selfenhancing identity work if the competitor was perceived to have higher status, as this communicated a positioning of both actors on a similar level. Similarly, denying competition with actors perceived as having lower status could also be regarded as identity self-enhancement, by positioning such actors on an inferior level of competition.

At the personal level, individuals competed or collaborated with other individuals both within and across organizations and types of organizations. An important influence on the potential for competition or collaboration was the complementarity or dissimilarity between individuals' expertise, which at times took primacy over organizational affiliation in personal identity work. Individuals from different organizations at times collaborated, while those from the same organization competed:

Competition between us occurs more with our university professors...I would say, it is sometimes more difficult to collaborate with an office neighbor in the same institution than with one in another university. So we collaborate fairly well with [representatives from] other universities. (AO2, Faculty Dean)

Academics, who need to publish for their personal advancement, were often in competition with their colleagues in the same organization. Collaboration and competition possibilities were thus fostered or hindered based on the extent to which individuals felt threatened by others who shared the same expertise.

At the organizational level, organizations competed or collaborated with other organizations or types of organizations through their representatives: “Already working with [certain] large organizations means that sometimes we can’t work with others” (AO2, Faculty Dean). Organizations with more differences had less organizational competition, making it easier to collaborate at the personal level, especially among those possessing similar individual expertise. Likewise, organizations with more similarities had more organizational competition, making it more difficult to collaborate at the personal level, especially among those with very 
different expertise or on projects involving "core” IP: "[SME] has nothing in their core IP so they're not in competition on this project, but maybe products or little overlapping parts can be in competition elsewhere" (OEM2, Product Architect). Universities were also in competition to establish partnerships that attracted an ever declining number of students.

We work with our friends from [another AO] even if they hate us. They always say we are the little brother they will crush...This is war, open war...And there are many things we see, we hear that we're the last to know because we're in open competition with [the other AO]. (AO1, R\&D Coordinator)

Across levels, competition at both levels hindered collaboration. For collaboration to be possible, actors had to be distinct enough at least at one level, as competition at one level hindered collaboration at the other level if actors were too similar. Two competing organizations might collaborate on a project assumed not to exacerbate their rivalry, which was recognized as a tour de force by many knowledgeable persons in the industry: "You wouldn't see collaborations emerge without a consortium like this. You wouldn't go work with a direct [organizational] competitor or see a [organizational] competitor and ask, 'Hey, would you do a project with me?'” (OEM2, Product Architect). On the contrary, innovation-driven collaboration between the organizations on other projects at times proved unmanageable, despite the consortium's IP agreement:

Even when there are several partners on the same project, if we are invited to work with one of our [organizational] competitors, it will limit innovation. It won't happen in all cases on all projects, but this perception will remain. The [individual] competitors will be tempted not to share precisely to avoid increasing competition. (SME3, R\&D Project Manager)

When two competing organizations tried to collaborate, their representatives had to compensate by becoming more conciliatory at the personal level—often by accentuating distinctions between their organizations. Alternatively, two representatives could become less conciliatory for personal reasons and avoid collaboration, despite a clear desire to collaborate at the organizational level.

The choices involved in the delicate balance between competing and collaborating made this tension central in identity work. These choices were closely linked to the perceived and subjective perceptions of distinctiveness and to the strategic translation process described 
previously, since competing actors could accentuate their differences, downplay their similarities and hide more information from each other, thereby increasing the level of decoding effort required. However, collaborating actors often put great effort into accurately translating in order to minimize the amount of decoding effort required of their partners.

\section{Overall cross-level identity tension: Between differentiating and imitating}

The more two actors imitated one another, the less distinctive they appeared, and vice versa. The overall tension between imitation and differentiation was found to be present within each level in our study, as well as between the personal and organizational levels. This overall cross-level tension reflects the notion of optimal distinctiveness (Leonardelli, Pickett \& Brewer, 2010) constituting the paradoxical dynamic at the heart of this form of identity work. Distinction at one level at times enabled imitation at the other level, leading to a form of isomorphism in actors' cross-level identity work that is more complex than what has been portrayed in prior network studies. We argue that this isomorphism is highly influenced by cross-level identity tensions between imitating and differentiating, and thus can only be described as "partial.”

At the personal level, individuals imitated or differentiated away from other individuals, especially those attached to a specific organization or type of organization. Whether they felt the need to improve their “project management skills” (SME1, R\&D Executive), “marketing knowledge” or “organizing capacity” (OEM1, R\&D Coordinator), or to become "increasingly involved in drafting and implementing projects” (AO1, R\&D Coordinator), representatives claimed that they advanced by participating in R\&D projects. While working together on mainstream and future industry trends, individuals and organizations often sought to differentiate their expertise from that of their counterparts in an effort to avoid entering into direct competition with them. Highly similar individuals at times felt the need to distinguish their expertise from others, and to safeguard these differences. For example, OEM representatives only reluctantly shared the distinctive integrated knowledge required to produce an entire aircraft. At the same time, very different individuals working on the same innovation project often felt the need to develop the expertise they lacked in order to facilitate collaboration and decrease dependence on others, thus fostering partner imitation. In the case of academics, this 
often implied developing better project management skills-improvements that were recognized by OEM partners: "Professors who have completed a few CRIAQ projects and others beginning their first CRIAQ project...we can tell the difference” (OEM1, R\&D Coordinator). Several OEM partners expressed appreciation for those "rare” academics with project management skills, and insisted the consortium provide specific training to overloaded academics who typically resist accepting additional tasks. General skills aside, ideal partners were those considered to be complementary on some dimension, meaning they presented expertise that was neither too similar nor too different.

At the organizational level, organizations (through their representatives) imitated or differentiated away from other organizations or types of organizations involved in several supply chains: "We also want to go towards the technologies our clients want to develop" (SME1, R\&D Executive). Dissimilar organizations attempted to foster collaboration by downplaying their differences and copying best organizational practices, whereas similar organizations attempted to differentiate or protect their sources of differentiation, such as their "core” intellectual properties: “It can’t touch your core [organizational] IP because this is what distinguishes you from the others” (OEM2, Product Architect).

Across levels, imitation tended to decrease the differences between actors, which increased competition within and across levels. Although our informants were far more prone to speak of organizations and their representatives as the same actors (indicating overlapping identities), some informants clearly distinguished between the two:

Previously I could set up a project with people, no problem. I did that for years at Bell, Bombardier. But set up projects between organizations? I had never done that and the CRIAQ brought it to me. (OEM1, R\&D Coordinator)

The above quotation illustrates one representative's recognition that managing collaboration among individuals requires different skills than managing cooperation between organizations. Extremely high differentiation tended to hinder collaboration within and across levels, although distant organizational expertise could be combined on a project through the similar personal expertise of their representatives. In parallel, collaboration involving highly differentiated personal expertise could be justified by the similar expertise of their organizations. The double requirement of distinguishing one's expertise while imitating one's counterpart appeared at both 
levels of interaction, and whether it occurred at the personal or the organizational level did not seem to matter as long as a sufficient distinction was apparent. Extremely similar expertise at both levels hardly justified collaboration, whereas extremely different expertise at both levels resulted in problematic collaboration. "Sufficient" expertise alignment at one level or the other permitted collaboration, and "sufficient" expertise differentiation at one level or the other justified collaboration, while avoiding excessive competition. Notably, the integrated knowledge of the OEM representatives from organizations at the top of the supply chain structure enabled them to withhold valuable information from representatives of other types of organizations without requiring further protection mechanisms, making them artificially "complementary" with any other types of representatives. Moreover, identity work to distinguish personal expertise seemed especially significant for the academic representatives, even among individuals from the same institution, whereas best practice imitation better applied to companies aiming to remain competitive.

\section{Discussion}

While elements of cross-level identity tensions have been previously described in studies on interorganizational arrangements, we have identified four specific tensions that have an impact on both personal and organizational identity work in a research consortium. These crosslevel tensions influence the identity work engaged in by R\&D partners as they attempt to facilitate interorganizational collaboration. In navigating these four tensions, isomorphism would be expected in the within-level processes of collaborating and imitating, consistent with the mechanism of contagion through interaction (Borgatti \& Foster, 2003), and the process of mimetic isomorphism in networks (Borgatti \& Halgin, 2011). However, the cross-level nature of these processes reveals a more nuanced portrait of members' evolution in networks that extends the processes involved in isomorphism to include identity concerns. Since imitation threatens personal and organizational identities, and since diversity (rather than homogeneity) fosters innovation, a more complex process prevents complete isomorphism in within-level and crosslevel identity work. Our study paints a more political and less deterministic portrait of the evolution of networks than indicated by previous research. By choosing to participate in a given research network—and to collaborate with specific collaborators within that network—an actor's 
personal and organizational identities can be influenced in ways that are difficult to foresee and control due to the impacts of different levels of interaction.

Building on previous work on isomorphism in networks, we suggest that isomorphism is also tempered by subtle and ongoing cross-level identity work tensions between IP protecting and concealing, communicative translating and decoding, and perceptions of market-based competing and collaborating. These tensions ultimately give rise to an overall cross-level tension of differentiating and imitating leading to a process of partial isomorphism that facilitates collaboration and innovation simultaneously in an omnipresent delicate balancing of interests at several levels. While complete isomorphism would threaten distinctiveness (and thus innovation through decreased diversity), actors in our case imitated others just enough to foster collaboration within and across levels. It seemed necessary for individuals and organizations to deal with these tensions in order to adapt to the consortium members' requirements and collaborate with partners, while remaining distinctive enough so to avoid direct competition. It was also in the interest of the collaborative innovation network to maintain enough diversity among its personal and organizational members to foster innovation while ensuring enough convergence to justify collaboration. This balance appears especially difficult to maintain when a network is characterized by strong power asymmetries.

Our findings shed further light on the nature of cross-level identity isomorphism (Ashforth et al., 2001), as it appears to have been contributed to and limited by these four crosslevel tensions. If there were no IP protection and concealment, all actors could offer the same technologies and develop the same personal expertise, seriously decreasing market competition and identity distinctions. If translation and decoding were not partial, information would flow freely, which would greatly facilitate identity imitation and collaboration at both levels. If there were no market competition, all actors could collaborate with the same organizational and personal actors, likely leading to even more similar choices. And finally, resources available for specific identity distinctions and identity work at the personal and organizational levels would be completely different and would occur through a different cross-level process.

The four cross-level tensions we identified thus highlight aspects of cross-level identity work that are difficult to discern when only one level of analysis is considered. In this sense, cross-level identity work involves a perceived need to remain distinctive and resist isomorphic 
pressure, while simultaneously building bridges toward potential collaborators. The problem is less about the coexistence of antagonistic resources for identity construction (Clarke et al., 2009) than the impossibility of promoting one aspect of a tension without reducing the other. The fundamental tension we observed in the identity work in the CRIAQ consortium existed between distinctiveness and imitation. When operating at multiple levels, this tension was a source of daily stress among partners, and explains the fragile equilibrium characterizing collaborative innovation projects. Indeed, this cross-level tension highlights a mixture of collaboration and competition often referred to as “coopetition” (Nalebuff, Brandenburger \& Maulana, 1996) at the organizational level. However, when one considers both the personal and organizational levels, the degree of coopetition at one level could constrain or enable the other. Interestingly enough, conflicts seem more likely when collaboration occurs at one level and competition at another level, as opposed to a mix of both at each level.

In addition to providing more specific and empirically-driven categories of identity work in the context of a research consortium, our study sheds further light on the stability-fluidity debate in identity work (Brown, 2015). Although identity might appear stable at one level, this outward stability might be necessary to enable more fluid identity work at another level. For instance, in our study: the protection of organizational IP enabled better information sharing and identity work at the personal level; more coherent personal translation permitted easier decoding of organizational interests; and stable organizational competition called for more extensive personal collaboration. The stability-fluidity tension within and across levels of interaction implies internal control of actors and the external influence of others (Huemer et al., 2009), whereas the ability of marginalized groups to craft more rewarding identities may be negatively impacted by “crystallizing activities” of those in more privileged positions (Tracy and Trethewey, 2005) in the network. In our case, ambitions, control over their development and the identity work of SMEs were clearly disrupted by larger and more influential actors in the consortium.

Our study also lends support to the notion that identity work tensions can be selfperpetuating (Beech et al., 2012), and challenges the view that successful identity work leads to resolution when tensions are acknowledged, as the conscious recognition of such tensions is likely to be even more difficult across levels of interaction. Similarly, the challenges associated 
with translating and decoding external images may be further explored as an additional aspect of “outward" identity work (Watson, 2008), as individuals personally connect to a wide variety of discourses at different levels of interaction. The notions of translating and decoding may shed further light on discursive practices involved in remedial organizational identity work in the face of external threats (Breit, 2014).

Finally, this cross-level study contributes to identity research by addressing interconnections between levels of empirical analysis of identity work in a real research network, as opposed to the majority of previous work which has been theoretical in nature (Hitt et al., 2007). Identity work situated at one identity level has the potential to contaminate or catalyze relationships at another identity level through identifiable cross-level tensions. Since strong personal and organizational identities may prevent change and learning (Corley \& Gioia, 2003), collaborations requiring adaptation may prove difficult or even impossible. And yet, these identity work tensions must ultimately be assessed and addressed if an effective superordinate identity (Argote \& Kane, 2009) or moral community (Browning, Beyer \& Shetler, 1995) is to be created. It is our hope that a better understanding of these cross-level identity tensions in innovation networks might accelerate the collaboration process and help organizations and their members manage their partners' expectations in highly competitive industries.

\section{Conclusions and future directions}

Our conception of cross-level identity work brings to the forefront the ongoing contextual co-construction and articulation of identities by actors at various levels in practice. This insight challenges the common expectation that more collaboration leads to more innovation and the widespread conception of a manageable identity, especially at the organizational level. "In the extreme case, the single organization is perceived as a self-sufficient entity whereby its managers believe, and/or act as if they are in sole control of relationships and their organization's identity" (Huemer et al., 2009: 56). This suggests once again that the identity of an organization is found both inside (in the interactions between its members), as well as outside (in its members' interactions with members of other organizations) (Bruner, 1990; Czarniawska, 1998; Huemer et al., 2009). Acting on behalf of their organizations and being perceived as such by others in networks, individuals work on their identities while working collectively with other 
organizational members on their organizations' identities; both processes occur across different levels of interaction in the same environment. To some extent, each context—whether an innovation network or another milieu—represents an additional opportunity to work on an identity with new situated local resources. Managerial control resides then in the careful choices made by the actors comprising an organization's internal and external networks and the nature of the relationships required to maintain them. Building on the theorizing of Ibarra et al. (2005), future research that more closely explores the impact of this cross-level identity work on the network itself might be fruitful.

Given the importance of achieving some form of stability with respect to the identity tensions identified in this and other interorganizational research on networks, researchers could explore mechanisms through which these tensions are maintained or resolved through multiple levels of interaction without slipping too far out of balance. If identities at one level of interaction enable and constrain identities at other levels (Ashforth et al., 2011), cross-level tensions should have repercussions not only for identity stability and fluidity considered at several levels, but also for other identity work themes identified by Brown et al. (2015). For example, how might identity ascribed at one level of interaction (structural aspects) enable or constrain the free choice of identity (agency aspects) at another level? How does the coherence of identity at one level permit identity fragmentation at another level? Could negative aspects of identity be balanced by positive dimensions at other levels? Or how might perceived authenticity of an identity at one level lead to identity contradictions at another level? Future research along these avenues might enable multi-level identity work to fulfill its promising potential to clarify some of the classic debates on identity among organization scholars. 


\section{Acknowledgements}

The authors thank the Consortium for Research and Innovation in Aerospace in Quebec for having kindly provided access to its members and activities. The authors would like to express their gratitude to the editor and the three anonymous reviewers for their assistance and constructive comments during the revision process, which clarified the focus and contribution of the study. 


\section{References}

Alvesson, M., \& Robertson, M. (2015). Money matters: Teflonic identity manoeuvring in the investment banking sector. Organization Studies, 37(1), 7-34.

Alvesson, M., Ashcraft, K. L., \& Thomas, R. (2008). Identity matters: Reflections on the construction of identity scholarship in organization studies. Organization, 15(1), 5-28.

Alvesson, M., \& Willmott, H. (2002). Identity regulation as organizational control: Producing the appropriate individual. Journal of Management Studies, 39(5), 619-644.

Argote, L., \& Kane, A. A. (2009). Superordinate identity and knowledge creation and transfer in organizations. In N. J. Foss \& S. Michailova (Eds.), Knowledge Governance (pp. 166190). Oxford: Oxford University Press.

Ashforth, B. E., Harrison, S. H., \& Corley, K. G. (2008). Identification in organizations: An examination of four fundamental questions. Journal of Management, 34(3), 325-374.

Ashforth, B., E., Rogers, K., M., \& Corley, K., G. (2011). Identity in organizations: Exploring cross-level dynamics. Organization Science, 22(5), 1144-1156.

Beech, N., Gilmore, C., Cochrane, E., \& Greig, G. (2012). Identity work as a response to tensions: A re-narration in opera rehearsals. Scandinavian Journal of Management, 28, 39-47.

Borgatti, S. P., \& Halgin, D. S. (2011). On network theory. Organization Science, 22(5), 11681181.

Borgatti, S. P., \& Foster, P. C. (2003). The network paradigm in organizational research: A review and typology. Journal of Management, 29.

Brass, D. J., Galaskiewicz, J., Greve, H. R., \& Tsai, W. (2004). Taking stock of networks and organizations: A multilevel perspective. Academy of Management Journal, 47(6), 795817.

Breit, E. (2014). Discursive practices of remedial organizational identity work: A study of the Norwegian Labor and Welfare Administration. Scandinavian Journal of Management, 30, 231-241.

Brown, A. (2015). Identities and identity work in organizations. International Journal of Management Reviews, 17(1), 20-40.

Brown, A.D., Lewis, M. (2011). Identity, discipline and routine. Organization Studies, 32(7), 871-895. 
Browning, L. D., Beyer, J. M., \& Shetler, J. C. (1995). Building cooperation in a competitive industry: Sematech and the semiconductor industry. Academy of Management Journal, 38(1), 113-151.

Bruner, J. (1990). Acts of Meaning. Cambridge, MA: Harvard University Press.

Carlile, P. R. (2004). Transferring, translating, and transforming: An integrative framework for managing knowledge across boundaries. Organization Science, 15(5), 555-568.

Chreim, S., Williams, B. E. B., \& Hinings, C. R. B. (2007). Interlevel influences on the reconstruction of professional role identity, Academy of Management Journal, 50(6), 1515-1539.

Clarke, C. A., Brown, A. D., \& Hailey, V. H. (2009). Working identities? Antagonistic discursive resources and managerial identity. Human Relations, 62(3), 323-352.

Clegg, S., R. , Rhodes, C., \& Kornberger, M. (2007). Desperately seeking legitimacy: Organizational identity and emerging industries. Organization Studies, 28(4): 495.

Corbin, J., \& Strauss, A. (2008). Basics of qualitative research (Third ed.). Los Angeles: Sage Publications.

Corley, K. G., \& Gioia, D. A. (2003). Semantic learning as change enabler: Relating organizational identity and organizational learning. In M. Easterby-Smith \& M. Lyles (Eds.), The Blackwell handbook of organizational learning and knowledge management: Blackwell.

Czarniawska, B., \& Wolff, R. (1998). Constructing new identities in established organization fields. International Studies of Management and Organization, 28, 32-56.

Ellis, N., \& Ybema, S. (2010). Marketing identities: Shifting circles of identification in interorganizational relationships. Organization Studies, 31, 279-305.

Emerson, D. (2012). Beyond the horizon: Canada's interests and future in aerospace. Ottawa: Industry Canada.

Gadde, L.-E., Huemer, L., \& Håkansson, H. (2003). Strategizing in industrial networks. Industrial Marketing Management, 32, 357-364.

Glynn, M. A. (2008). Beyond constraint: How institutions enables identities. In R. Greenwood, C. Oliver, K. Sahlin, \& R. Suddaby (Eds.), The Sage handbook of organizational institutionalism (413-422). London: Sage Publications. 
Henderson, L. S. (2004). Encoding and decoding communication competencies in project management - an exploratory study. International Journal of Project Management, 22, 469-476.

Hitt, M. A., Beamish, P. W., Jackson, S. E., \& Mathieu, J. E. (2007). Building theoretical and empirical bridges across levels: Multilevel research in management, Academy of Management Journal, 50(6), 1385-1399.

Huemer, L. (2013). When in Rome, be(come) a Roman? An actor focus on identities in networks. Industrial Marketing Management, 42, 1112-1120.

Huemer, L., Håkansson, H., \& Prenkert, F. (2009). The becoming of Cermaq: The interplay between network influences and firm level control ambitions. The IMP Journal, 3(3), 5375.

Huemer, L., Becerra, M., \& Lunnan, R. (2004). Organizational identity and network identification: relating within and beyond imaginary boundaries. Scandinavian Journal of Management, 20, 53-73.

Ibarra, H., Kilduff, M., \& Tsai, W. (2005). Zooming in and out: Connecting individuals and collectivities at the frontiers of organizational network research, Organization Science, 16(4), 359-371.

Jacobs, C., Oliver, D., \& Heracleous, L. (2013). Diagnosing organizational identity beliefs by eliciting complex, multimodal metaphors, Journal of Applied Behavioral Science, 49(3), 485-507.

Järventie-Thesleff, R., \& Tienari, J. (2015). Roles as mediators in identity work. Organization Studies, 37(2), 237-265.

Johansson, U., \& Elg, U. (2002). Relationships as entry barriers: A network perspective. Scandinavian Journal of Management, 18, 393-419.

Kane, A. A. (2010). Unlocking knowledge transfer potential: Knowledge demonstrability and superordinate social identity. Organization Science, 21(3), 643-660.

Katila, R., Rosenberger, J.D. \& Eisenhardt, K.M. (2008). Swimming with sharks: technology ventures, defense mechanisms and corporate relationships. Administrative Science Quarterly, 53, 295-332. 
Kreiner, G. E., Hollensbe, E. C., \& Sheep, M. L. (2006). On the edge of identity: Boundary dynamics at the interface of individual and organizational identities. Human Relations, 59(10), 1315-1341.

Leonardelli, G. J., Pickett, C. L., \& Brewer, M. B. (2010). Optimal distinctiveness theory: A framework for social identity, social cognition, and intergroup relations. In M. P. Zanna \& J. M. Olson (Eds.), Advances in Experimental Social Psychology (63-113). San Diego: Elsevier.

Marchington, M., \& Vincent, S. (2004). Analyzing the influence of institutional, organizational and interpersonal forces in shaping inter-organizational relations. Journal of Management Studies, 41(6), 1029-1056.

McInnes, P., \& Corlett, S. (2012). Conversational identity work in everyday interaction. Scandinavian Journal of Management, 28, 27-38.

Nalebuff, B. J., Brandenburger, A \& Maulana, A. (1996). Co-opetition. London: Harper Collins Business.

Oliver, A. L. (2004). On the duality of competition and collaboration: network-based knowledge relations in the biotechnology industry. Scandinavian Journal of Management, 20, 151171.

Oliver, D. (2015). Identity work as a strategic practice. In D. Golsorkhi, L. Rouleau, D. Seidl, \& E. Vaara (Eds.), Cambridge handbook of strategy as practice, 2nd ed.: 331-344. Cambridge, United Kingdom: Cambridge University Press.

Patton, M. Q. (2002). Qualitative evaluation and research methods (Third ed.). Thousand Oaks: Sage Publications.

Sveningsson, S., \& Alvesson, M. (2003). Managing managerial identities: Organizational fragmentation, discourse and identity struggle. Human Relations, 56(10), 1163-1193.

Tracy, S. J., \& Trethewey, A. (2005). Fracturing the real-self fake-self dichotomy: Moving toward "crystallized" organizational discourses and identities. Communication Theory, 15(2), 168-195.

Watson, T., J. (2008). Managing identity: Identity work, personal predicaments and structural circumstances. Organization, 15(1), 121-143.

Yin, R. K. (2003). Case study research: Design and methods (Third ed.). Thousand Oaks: Sage Publications. 